Article

\title{
Biomass-Derived Porous Carbon from Agar as an Anode Material for Lithium-Ion Batteries
}

\author{
Nurbolat Issatayev ${ }^{1,2}$, Gulnur Kalimuldina ${ }^{3, *}$, , Arailym Nurpeissova ${ }^{1}$ and Zhumabay Bakenov ${ }^{1,2, *(\mathbb{D})}$ \\ 1 National Laboratory Astana, Nazarbayev University, Kabanbay Batyr Ave. 53, \\ Nur-Sultan 010000, Kazakhstan; nurbolat.issatayev@nu.edu.kz (N.I.); arailym.nurpeissova@nu.edu.kz (A.N.) \\ 2 Department of Chemical and Materials Engineering, School of Engineering and Digital Sciences, Nazarbayev \\ University, Kabanbay Batyr Ave. 53, Nur-Sultan 010000, Kazakhstan \\ 3 Department of Mechanical and Aerospace Engineering, School of Engineering and Digital Sciences, \\ Nazarbayev University, Kabanbay Batyr Ave. 53, Nur-Sultan 010000, Kazakhstan \\ * Correspondence: authors: gkalimuldina@nu.edu.kz (G.K.); zbakenov@nu.edu.kz (Z.B.); \\ Tel.: +7-717-269-4578 (G.K.); +7-717-270-6530 (Z.B.)
}

Citation: Issatayev, N.; Kalimuldina, G.; Nurpeissova, A.; Bakenov, Z. Biomass-Derived Porous Carbon from Agar as an Anode Material for Lithium-Ion Batteries. Nanomaterials 2022, 12, 22. https://doi.org/ $10.3390 /$ nano12010022

Academic Editors: Marc Cretin Sophie Tingry and Zhenghua Tang

Received: 9 November 2021

Accepted: 17 December 2021

Published: 22 December 2021

Publisher's Note: MDPI stays neutral with regard to jurisdictional claims in published maps and institutional affiliations.

Copyright: (C) 2021 by the authors. Licensee MDPI, Basel, Switzerland. This article is an open access article distributed under the terms and conditions of the Creative Commons Attribution (CC BY) license (https:// creativecommons.org/licenses/by/ $4.0 /)$.

\begin{abstract}
New porous activated carbons with a high surface area as an anode material for lithium-ion batteries (LIBs) were synthesized by a one-step, sustainable, and environmentally friendly method. Four chemical activators- $\mathrm{H}_{2} \mathrm{SO}_{4}, \mathrm{H}_{3} \mathrm{PO}_{4}, \mathrm{KOH}$, and $\mathrm{ZnCl}_{2}$-have been investigated as facilitators of the formation of the porous structure of activated carbon $(\mathrm{AC})$ from an agar precursor. The study of the materials by Brunauer-Emmett-Teller (BET) and scanning electron microscopy (SEM) methods revealed its highly porous meso- and macro-structure. Among the used chemical activators, the AC prepared with the addition of $\mathrm{KOH}$ demonstrated the best electrochemical performance upon its reaction with lithium metal. The initial discharge capacity reached $931 \mathrm{mAh} \mathrm{g}^{-1}$ and a reversible capacity of $320 \mathrm{mAh} \mathrm{g}^{-1}$ was maintained over 100 cycles at $0.1 \mathrm{C}$. High rate cycling tests up to $10 \mathrm{C}$ demonstrated stable cycling performance of the AC from agar.
\end{abstract}

Keywords: activated carbon; agar; anode; lithium-ion battery; chemical activators

\section{Introduction}

Lithium-ion batteries (LIBs) are conquering the worldwide market due to their high specific capacity, absence of memory effect, long service life, and stable operation [1-5]. LIBs are extensively used in portable electronics applications and are currently expanding into the field of plug-in hybrid and electric vehicles [6]. Thus, the requirements for LIBs are increasing not only in terms of specific energy of its components (cathode, anode) but also in their eco-friendliness owing to growing awareness of environmental issues. Therefore, the development of electrode materials that correspond to the stated requirements is in high demand.

Nowadays, in commercially available LIBs, graphite is mainly used as an anode material. Despite this fact, some critical shortcomings are associated with graphite-such as a low specific capacity, poor rate capability, and slow charge-discharge processes-limiting their applicability in the next generation technologies in electronics and electric transport. Furthermore, it is worth mentioning the high cost and negative environmental impact due to its synthesis from fossil carbon sources such as coal and petroleum coke [7]. Therefore, it is highly desirable to explore alternative negative electrode materials for Li-ions such as tin [8,9], transition metal oxides [10-13], silicon [14,15], and others. Although the alternative anodes can provide higher specific capacity, they suffer from substantial volume changes during insertion/extraction of Li-ions causing materials disintegration leading to huge irreversible capacity loss and poor cyclability. The challenges faced by noncarbon anode materials hinder their broad application in the next-generation LIBs. Hence, considerable research efforts continue on the development of carbonaceous materials for high-capacity anodes, especially for the porous carbon materials with the high surface area 
were extensively researched due to their enhanced electrochemical performance in reaction with Li-ions [16]. This improvement has been associated with porous structure that forms shorter distances for Li-ions and electrons to travel, facilitating enhanced charge transfer, diffusion rate, and better kinetics [17].

Various types of biomass have been intensively researched as a promising renewable source to prepare porous and functional carbon materials. Their low cost, tunable physi$\mathrm{cal} /$ chemical properties, recyclability, abundant availability, and harmony with the environment are especially of high interest [18]. Two mechanisms of Li-ion storage in carbonaceous materials derived from biomass can be defined as the invertible lithiation/delithiation into/out of the expanded graphitic layers and the surface-induced capacitive behavior summoned by pores, regions of structural defects, and functional groups [19]. Pursuant to earlier research, biomass activated carbon nanostructures can be produced and generated from a variety of natural resources such as rice husk [20], wheat stalk [21], cellulose [22], green tea wastes [23], natural cotton [24], puffed corn [25], sucrose [26].

Physical activation [27], chemical activation [28], catalytic activation [29], and microwave activation [30] are commonly used methods for producing biomass-derived AC materials. Among them, chemical activation is extensively utilized to produce porous carbon due to its advantages over other activation methods-such as high yield, less surface damage, low activation temperature, and short reaction time. During the activation process, an activator is usually added to form a new porous structure to increase the specific surface area of the material. The most common chemical activators are Bronsted $\left(\mathrm{H}_{2} \mathrm{SO}_{4}\right.$, $\left.\mathrm{H}_{3} \mathrm{PO}_{4}\right)$ [31], Lewis acids $\left(\mathrm{CuCl}_{2}\right.$ and $\left.\mathrm{ZnCl}_{2}\right)$ [32], alkali metal hydroxides, and carbonates $\left(\mathrm{NaOH}, \mathrm{KOH}, \mathrm{K}_{2} \mathrm{CO}_{3}, \mathrm{Na}_{2} \mathrm{CO}_{3}\right)$ [33-35].

In this work, we propose a facile method of preparation of $\mathrm{AC}$ material with a large surface area and a developed porous structure from agar. Agar biopolymer was used as a carbon precursor due to its low cost, high carbon content, and the lack of any traces of heavy metals. The pore formation and expanding effect of chemical activators as $\mathrm{H}_{2} \mathrm{SO}_{4}, \mathrm{H}_{3} \mathrm{PO}_{4}$, $\mathrm{KOH}$, and $\mathrm{ZnCl}_{2}$ on the $\mathrm{AC}$ morphology were compared and studied. The materials were examined as an anode for LIBs and demonstrated high capacity and excellent cycling and rate characteristics. To the best of our knowledge, this is the first application of agar activated carbon as anode for LIBs. Previous studies of activated carbon with agar precursor have been investigated for supercapacitors [36,37]. In addition, the activation of agar at the molecular level was performed according to the method described by Chen et al. [36], which requires a one-step calcination of the agar without high-temperature carbonation.

\section{Materials and Methods}

Agar, $\mathrm{KOH}, \mathrm{H}_{3} \mathrm{PO}_{4}, \mathrm{H}_{2} \mathrm{SO}_{4}, \mathrm{ZnCl}_{2}$, and $\mathrm{HCl}$ were purchased from Sigma-Aldrich (St. Louis, MO, Germany). All the reagents were analytical grade and used as received without further purifications.

\subsection{Fabrication of the Activated Carbon}

For preparing the porous activated carbon material, $0.25 \mathrm{~g}$ of each $\mathrm{KOH}, \mathrm{H}_{3} \mathrm{PO}_{4}$, $\mathrm{H}_{2} \mathrm{SO}_{4}$, and $\mathrm{ZnCl}_{2}$ was mixed with agar separately in $10 \mathrm{~mL}$ water (DI) at $95^{\circ} \mathrm{C}$. The mixture was stirred until homogeneous hydrogels were obtained. After cooling to room temperature, the mixture was further freeze-dried for $24 \mathrm{~h}$. The sample was pyrolyzed at $800{ }^{\circ} \mathrm{C}$ (the heat treatment steps are shown schematically in Scheme 1) in a conventional furnace for $2 \mathrm{~h}$ in argon. Finally, after rinsing with $10 \% \mathrm{HCl}$ and an ample amount of water, the activated carbon was dried at $70{ }^{\circ} \mathrm{C}$ in a vacuum oven for $24 \mathrm{~h}$. The preparation route is illustrated in Figure 1. The final agar-derived activated by $\mathrm{KOH}, \mathrm{H}_{3} \mathrm{PO}_{4}, \mathrm{H}_{2} \mathrm{SO}_{4}$, and $\mathrm{ZnCl}_{2}$ carbons were denoted as KAAC, PAAC, SAAC, and ZAAC, respectively. 


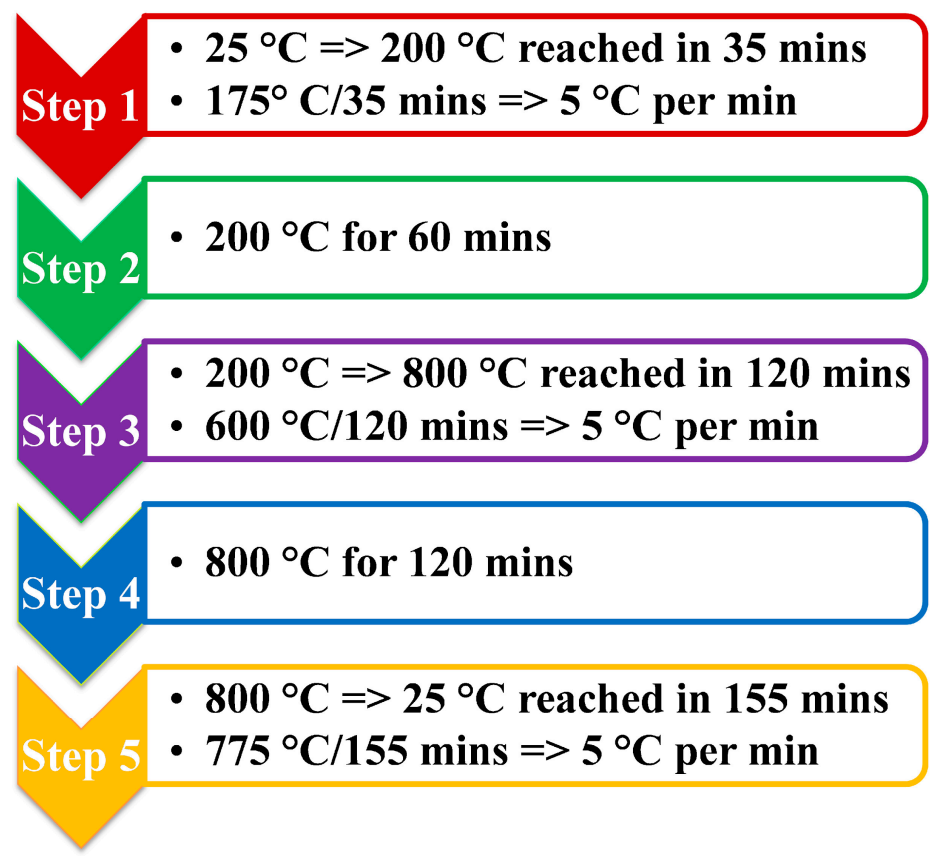

Scheme 1. Optimal temperature and time for preparation of AC from agar.

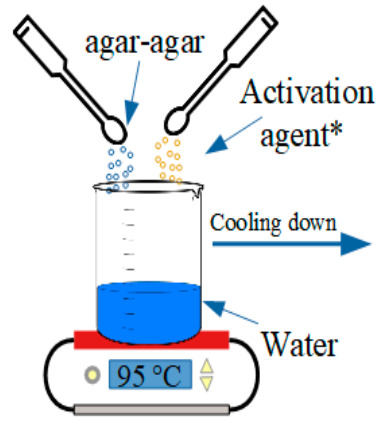

* a) $\mathrm{KOH}$; b) $\mathrm{ZnCl}_{2}$ c) $\mathrm{H}_{2} \mathrm{SO}_{4}$;

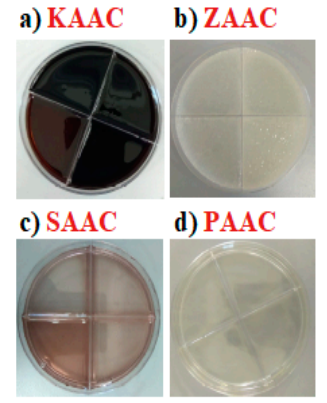

d) $\mathrm{H}_{3} \mathrm{PO}_{4}$

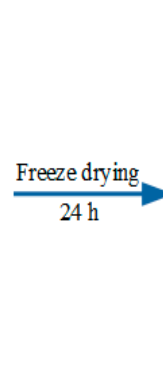

Quartz tub
Tubular furnace

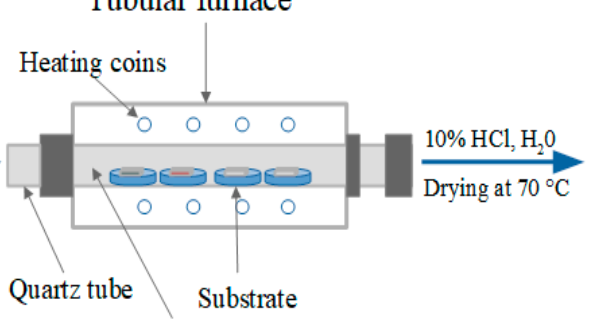

Reaction chamber (inert atmosphere)
Activated carbon

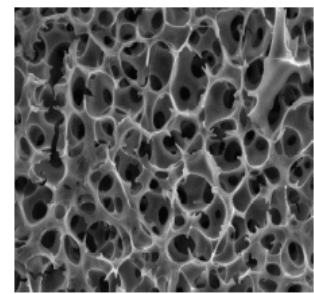

Figure 1. Preparation method of $\mathrm{AC}$ with four different activating agents: (a) $\mathrm{KOH}$; (b) $\mathrm{ZnCl}_{2}$; (c) $\mathrm{H}_{2} \mathrm{SO}_{4} ;$ (d) $\mathrm{H}_{3} \mathrm{PO}_{4}$.

\subsection{Characterizations}

The resulting AC powders were analyzed by Raman spectroscopy (Horiba LabRam Evolution) with a $633 \mathrm{~nm}$ excitation laser range from 200 to $2000 \mathrm{~cm}^{-1}$. The functional groups of the ACs were examined using Nicolet iS10 Fourier Transform Infrared (FTIR) Spectrometer in the range of $400-4000 \mathrm{~cm}^{-1}$ and X-ray photoelectron spectrometer (XPS)NEXSA (Thermo Scientific, Waltham, MA, USA). The morphology of the disordered carbons was observed by scanning electron microscope Crossbeam 540 (SEM, Zeiss, Germany) and transmission electron microscope JEOL JEM-1400 Plus (TEM, JEOL, Peabody, MA, USA). Thermogravimetric analysis (TGA) was carried out by Simultaneous Thermal Analyzer (STA, PerkinElmer, Waltham, MA, USA) 6000 at a heating rate of $10{ }^{\circ} \mathrm{C} \mathrm{min}{ }^{-1}$ from 30 to $800{ }^{\circ} \mathrm{C}$ in nitrogen $\left(\mathrm{N}_{2}\right)$. The surface area and pore size distribution of the powders were studied by $\mathrm{N}_{2}$ adsorption on Autosorb $\mathrm{iQ}$ and ASiQwin gas sorption system (Quantachrome instruments; Boynton Beach, FL, USA).

\subsection{Cell Preparation}

The electrochemical activity of the carbon samples was examined using CR2032-type coin cells. The electrodes were prepared by mixing the obtained ACs, carbon black (SuperP), and polyvinylidene fluoride (PVDF) in the ratio of 8:1:1 in N-methyl-2-pyrrolidone 
(NMP). The resulting mixture was then applied onto copper foil using the Doctor Blade technique and then dried overnight at $60{ }^{\circ} \mathrm{C}$ in a vacuum oven. The coated copper foil was cut into the disks with a diameter of $14 \mathrm{~mm}$. The mass loadings of the active materials were approximately $1-1.5 \mathrm{mg} \mathrm{cm}^{-2}$. The cells were assembled in an argon-filled glove box (MBRAUN, LABmaster Pro Glovebox, Germany, containing $<0.1 \mathrm{ppm} \mathrm{O}_{2}$ and $<0.1 \mathrm{ppm} \mathrm{H}_{2} \mathrm{O}$ ) using lithium metal foil as the counter and reference electrode. A $1 \mathrm{M}$ $\mathrm{LiPF}_{6}$ in ethylene carbonate (EC) and dimethyl carbonate (DMC) $(1: 1, \mathrm{v} / \mathrm{v})$ was used as an electrolyte solution and a polypropylene membrane (Celgard $\left.{ }^{\circledR} 2400\right)$ as a separator. Each cell contains $150 \mu \mathrm{L}$ of electrolyte. Galvanostatic cycling of the electrodes was investigated by a multichannel battery testing system (Arbin Inc. and Neware Battery tester, Neware Co., Shenzhen, China) between the cut-off potentials of 0.01 and $3.0 \mathrm{~V} \mathrm{vs.} \mathrm{Li}^{+} / \mathrm{Li}$ at a current density of 0.1 and $1.0 \mathrm{C}$ for 100 cycles. Cyclic voltammetry (CV) measurements were performed using a VMP3 potentiostat/galvanostat (Bio-Logic Science Instrument Co.) in a potential range of $0.01-3.0 \mathrm{~V}$ at a scan rate of $0.1 \mathrm{mV} \mathrm{s}^{-1}$.

\section{Results and Discussion}

The TGA curves (Figure 2a) for all samples, including pure agar, consist of two distinct zones. At the first step, the weight loss of around $5-10 \%$ was registered at the temperatures around $50-130{ }^{\circ} \mathrm{C}$ which can be associated with water loss. Then there is an abrupt transition at about $210^{\circ} \mathrm{C}$, indicating that the decomposition process involves rapid weight loss. At the temperature of $800{ }^{\circ} \mathrm{C}$, the weight loss reaches approximately $85.5 \%, 87.2 \%$, $83.3 \%, 73.4 \%$, and $60.2 \%$ for pure agar, SAAC, ZAAC, PAAC, and KAAC, respectively. Comparison of the obtained activated carbons illustrates that $\mathrm{KOH}$ activation results in a lower peak temperature, shorter pyrolysis duration, and thermal decomposition at a higher instantaneous rate. These results also imply that the activation of $\mathrm{KOH}$ and $\mathrm{H}_{3} \mathrm{PO}_{4}$ is faster and easier than the activation of $\mathrm{H}_{2} \mathrm{SO}_{4}$ and $\mathrm{ZnCl}_{2}$.

The structural characteristics of obtained AC were investigated by Raman spectroscopy, as illustrated in Figure 2b. The patterns of all four samples showed two distinct peaks for the $G$ band at about $1580 \mathrm{~cm}^{-1}$ assigned to carbon atoms with the $\mathrm{sp}^{2}$ electronic configuration in the structure of the graphite sheet, and the $D$ band at about $1340 \mathrm{~cm}^{-1}$, which corresponds to the presence of a disordered and defective structure of carbon materials. The degree of disorder in carbon can be evaluated from the ratio of the integrated intensities of the D-band to the G-band $\left(\mathrm{I}_{\mathrm{D}} / \mathrm{I}_{\mathrm{G}}\right)$, and higher values represent a greater number of imperfection in carbon atoms. The $\mathrm{I}_{\mathrm{D}} / \mathrm{I}_{\mathrm{G}}$ ratios of $\mathrm{KAAC}, \mathrm{PAAC}, \mathrm{SAAC}$, and ZAAC are $1.02,0.99,0.98$, and 0.97 , respectively. It can be seen that the ratio of $\mathrm{I}_{\mathrm{D}} / \mathrm{I}_{\mathrm{G}}>1$ for the $\mathrm{KOH}$ sample, which emphasizes the largest number of defects and boundaries in the resulting $\mathrm{sp}^{2}$-hybridized graphene sheet. A decrease in the ratio for the other three samples $(<1)$ indicates a decrease in the number of voids or defects and, therefore, an upper degree of graphitization [38]. However, all four samples illustrate the high-intensity ratio, which indicates a high amorphous degree, edges, and other defects.

Furthermore, the structural characteristics of the materials were studied by FT-IR spectroscopy. As shown in Figure 2c, all obtained ACs retain some functional group of agar. From the FT-IR spectra, one can observe vibrational peaks at approximately $3650 \mathrm{~cm}^{-1}$ which illustrates the -OH (hydroxyl) group and at around $2905 \mathrm{~cm}^{-1}$ attributed to the $-\mathrm{CH}_{3} \mathrm{O}$ - (methoxyl) group. In addition, the presence of the peaks at about $933 \mathrm{~cm}^{-1}$ and $1075 \mathrm{~cm}^{-1}$ are related to the 3,6-anhydrogalactose bridges. However, some peaks of the obtained ACs are less intense. This can be explained by the cleavage of some functional groups during activation [39]. For example, in the process of activation with $\mathrm{KOH}$, it was suggested that the cyclic ether bond of six-membered rings and hydroxyl groups with hydrogen bonds in agar undergoes a dehydration reaction with potassium hydroxide, which is clearly seen from a decrease in the intensity of broad absorption, the band at $3650 \mathrm{~cm}^{-1}$ and the peak at $1075 \mathrm{~cm}^{-1}$ [40,41]. Analysis of the XPS spectra on the ACs $\mathrm{C} 1 \mathrm{~s}$ confirmed the partial graphitization and the presence of oxygen functional groups on 
the surface and is in good agreement with the results of Raman and FT-IR spectroscopy (Figure S1).
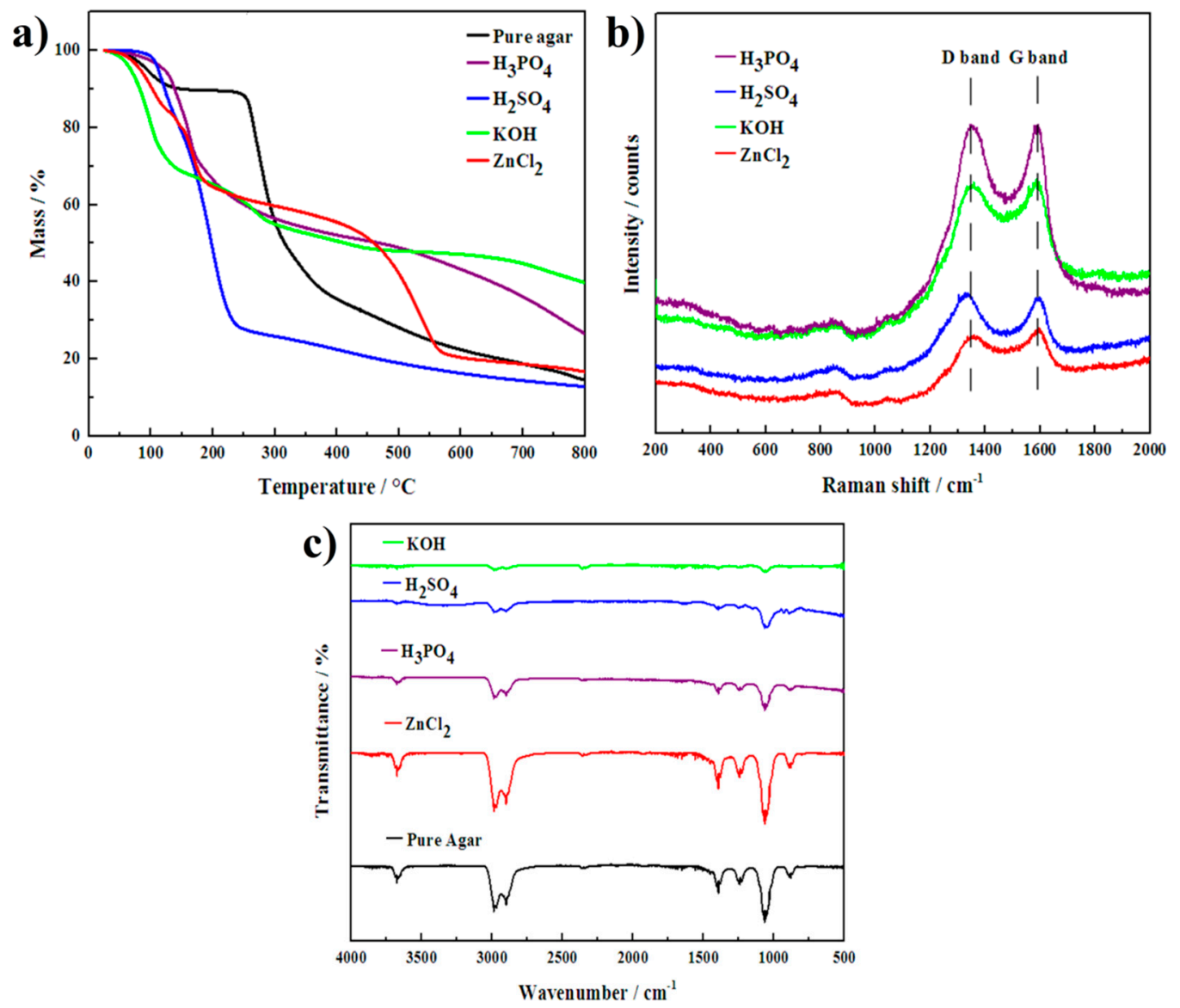

Figure 2. (a) TGA curves of pure agar and hydrogels with different activating agents; (b) Raman spectra of obtained carbons; (c) FT-IR spectra of pure agar and obtained carbons.

The morphological characteristics of ACs were studied using SEM as shown in Figure 3. All samples have a porous three-dimensional (3D) structure, which facilitates the better access of the electrolyte to the active material and accelerates the migration of electrons and ions when the materials are used in LIBs. KAAC and ZAAC have a similar 3D interconnected hierarchical structure with meso- and microporous morphology as illustrated in Figure 3a,b. Acid-ACs have similar 3D structures with mesopores (Figure 3c,d). However, the pore sizes of the resulting materials differ, which is discussed further below. Further TEM analysis was performed for the ACs. A disordered hierarchical porous structure can be observed that contains meso- and micro-pores (see Figure S2). The presence of abundant pores in the ACs from the agar can be identified by the large number of white spots between the disordered carbon layers [42]. 

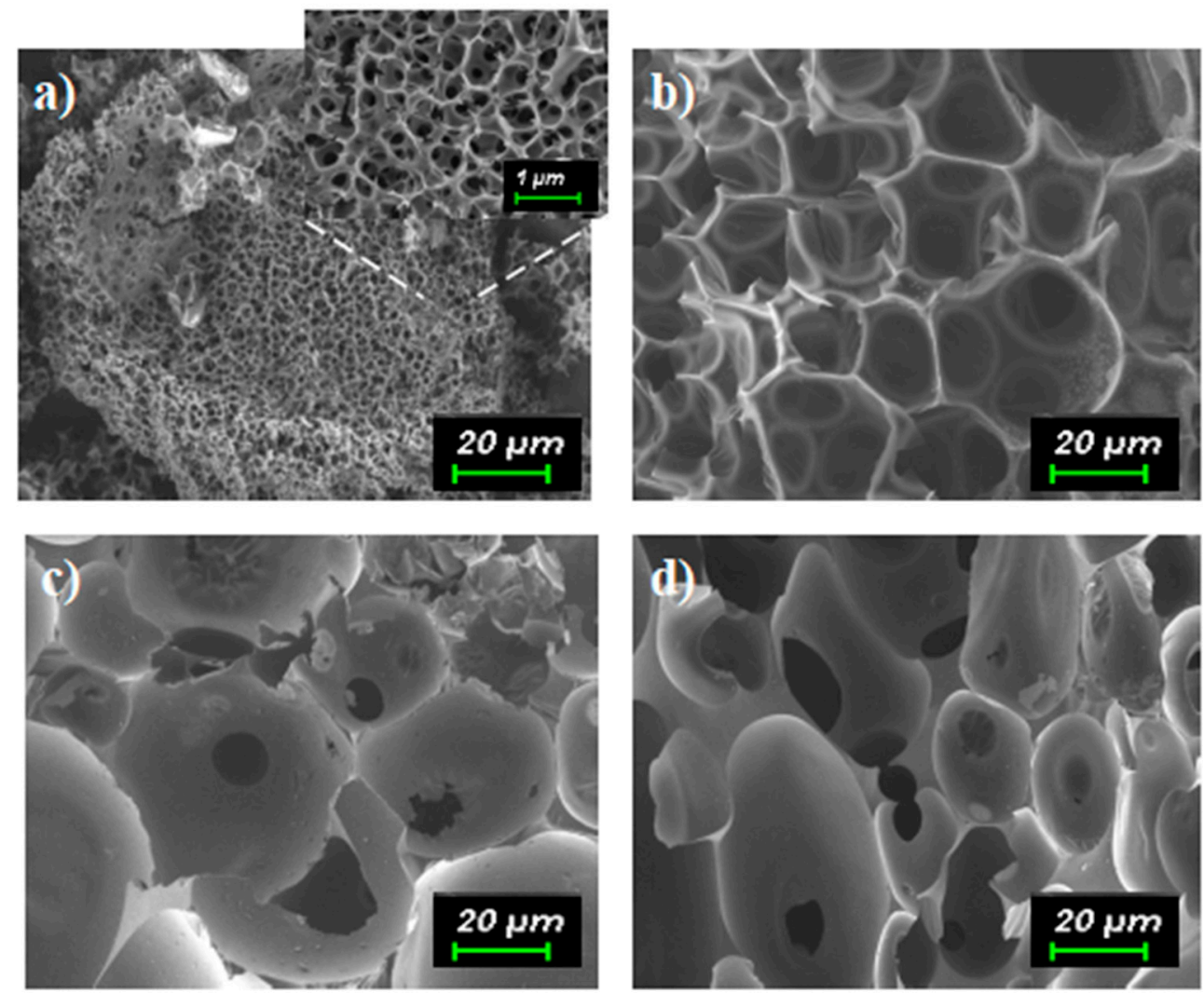

Figure 3. SEM images of ACs with four different activating agents: (a) KAAC; (b) ZAAC; (c) SAAC; (d) PAAC.

The detailed studies of the porous structure and surface of ACs were carried out by nitrogen adsorption measurements. As shown in Figure 4a, all samples demonstrate a type IV desorption isotherm. When relative pressure is above 0.8 , the isotherm increases significantly due to capillary condensation. The desorption isotherm is situated over the adsorption isotherm, which means that the samples have a high amount of mesopores [43]. In Figure $4 b$, which shows pore size distribution diagrams, it can be seen that the pore size ranges from 12 to $60 \mathrm{~nm}$. The specific surface areas for KAAC, ZAAC, PAAC, and SAAC were defined as $2417.5,3309.0,974.1$, and $548.3 \mathrm{~m}^{2} \mathrm{~g}^{-1}$, while the average pore size was $15.2,19.5,19.2$, and $19.0 \mathrm{~nm}$, respectively. The results indicate that the acid activators and $\mathrm{ZnCl}_{2}$ tend to form a mesoporous structure, while using a $\mathrm{KOH}$ activator results in mesoand macroporous structures.

The prepared ACs were tested as anode materials in LIBs. Figure 5a,b show the charge-discharge profiles of the electrodes at a charge-discharge rate of $0.1 \mathrm{C}$. At the initial cycle, KAAC, PAAC, SAAC, and ZAAC exhibited charge/discharge capacities of 360/836, $311 / 1018,230 / 564$, and 110/597 $\mathrm{mAh} \mathrm{g}^{-1}$, respectively. The Coulombic efficiencies were $42.9 \%, 30.5 \%, 40.8 \%$ and $18.4 \%$ for KAAC, PAAC, SAAC, and ZAAC, respectively. The low Coulombic efficiency in the 1st cycle is caused by the decomposition of the electrolyte, the formation of an SEI layer, and some irreversible capture of $\mathrm{Li}$ ions in a special position of the carbonaceous material, which may be associated with a surface reaction, for example, near residual $\mathrm{H}$ atoms [44]. At the 10th cycle, the charge-specific capacities for KAAC, PAAC, SAAC, and ZAAC were 290, 292, 169, and $123 \mathrm{mAh} \mathrm{g}^{-1}$, while the discharge-specific capacities were $309,337,174$, and $132 \mathrm{mAh} \mathrm{g}^{-1}$, respectively. The Coulombic efficiency improved significantly in the 10th cycle and amounted to $95,88,97$, and $96 \%$, respectively. The increase in the Coulombic efficiency might be in the formation of a stabilized SEI film. The SEI layer acts as a passivation layer, the formation of which is advantageous for carbon anodes as it prevents the continuous electrolyte decomposition on the activated carbon electrode, and therefore the anode is in a stable state [7]. 

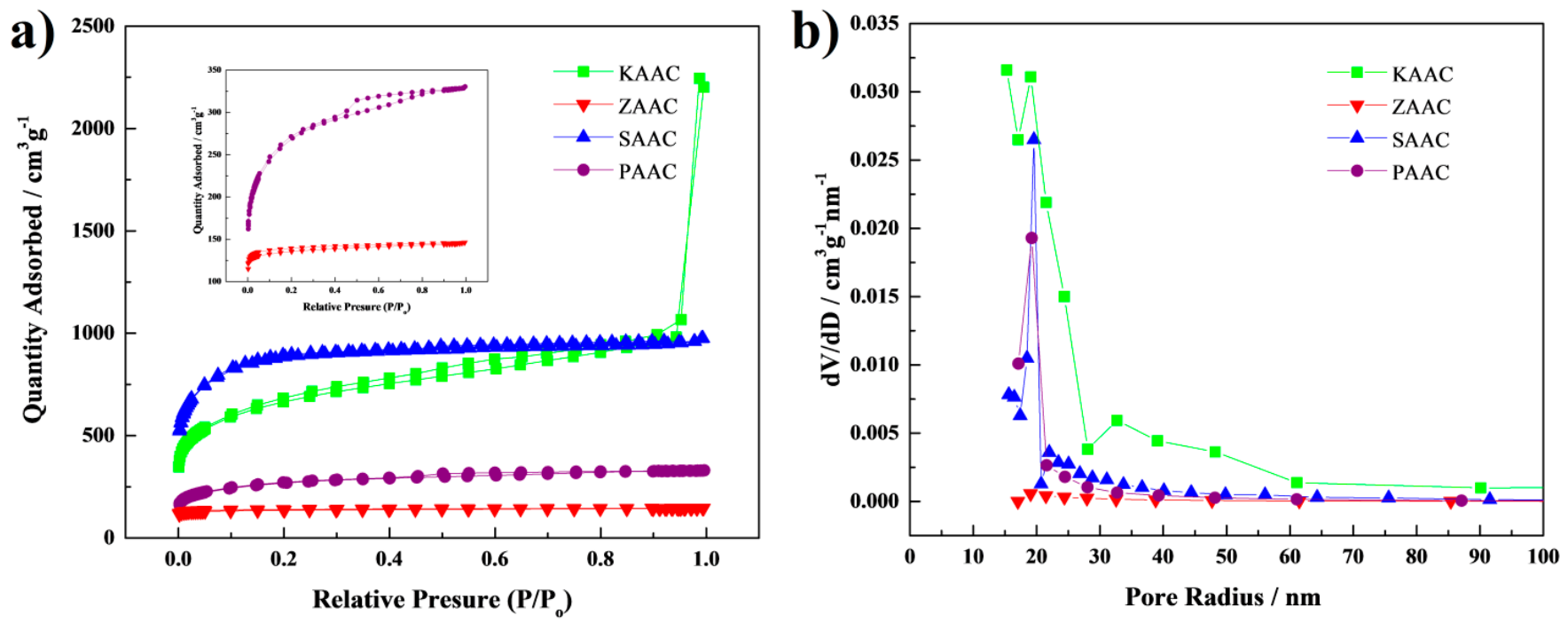

Figure 4. (a) Nitrogen adsorption-desorption isotherms and (b) pore sizes distribution.

The CV curves of the samples ranging from 0.01 to $2.8 \mathrm{~V}$ (versus $\mathrm{Li} / \mathrm{Li}^{+}$) at a scan rate of $0.1 \mathrm{mV} \mathrm{s}^{-1}$ are illustrated in Figure $5 \mathrm{e}, \mathrm{f}$. It is clearly seen that the 1 st cycle differs from the second and fifth cycles. The area of the reduction peak of the 1st cycle is more significant than that of the second and fifth cycles. This difference is associated with the non-reversible intercalation of Li-ions into the ACs [45]. There are two peaks for KAAC at around $0.01-0.2 \mathrm{~V}$ and $0.45 \mathrm{~V}$ at the first cycle. The latter peak corresponds to the decomposition and generation of SEI on the surface of carbon that disappears in subsequent cycles owing to the stabilization of the SEI layer. The influence of the SEI layer is vital for the CV cycle and Coulombic efficiency [46]. Consequently, at the first cycle, the Coulomb efficiency was low as shown in Figure 5, but in further cycles, it stabilized. A peak around $0.01 \mathrm{~V}$ is related to the incorporation of Li-ions into the layered carbon, and a flat peak between 0.2 and $0.6 \mathrm{~V}$ is attributed to the extracting process of Li-ions from the electrode [47]. The CV curves of the second and fifth cycles have a partial overlap, which indicates the outstanding stability of the electrode material.

To investigate the cyclic stability of the prepared carbons, the cells were galvanostatically cycled at current densities of $0.1 \mathrm{C}$ and $1 \mathrm{C}$ for 100 cycles as shown in Figure 5c,d. The stable discharge capacity of KAAC was the highest reversible capacity at 0.1 and $1 \mathrm{C}$ compared to PAAC, SAAC, and ZAAC. The specific capacity for KAAC, PAAC, SAAC, and ZAAC was 330, 239, 212, and $157 \mathrm{mAh} \mathrm{g}^{-1}$ at $0.1 \mathrm{~A} \mathrm{~g}^{-1}$ and 190, 150, 136, and $79 \mathrm{mAh}$ $\mathrm{g}^{-1}$ at $1 \mathrm{C}$, respectively. The reversible capacity of KAAC is higher than recently reported ACs obtained from cherry pit activated with $\mathrm{KOH}$ and $\mathrm{H}_{3} \mathrm{PO}_{4}$ [48]. Comparison with other bio-derived activated carbons is illustrated in Table 1 . Although upon the initial cycles the Coulombic efficiency of all samples was low, it increased upon further cycling and reached almost $100 \%$. These results demonstrate the excellent cycling capability and reversibility of all samples. Such tendencies can be observed practically for bio-mass derived activated carbon used as anode materials [7,48,49]. 

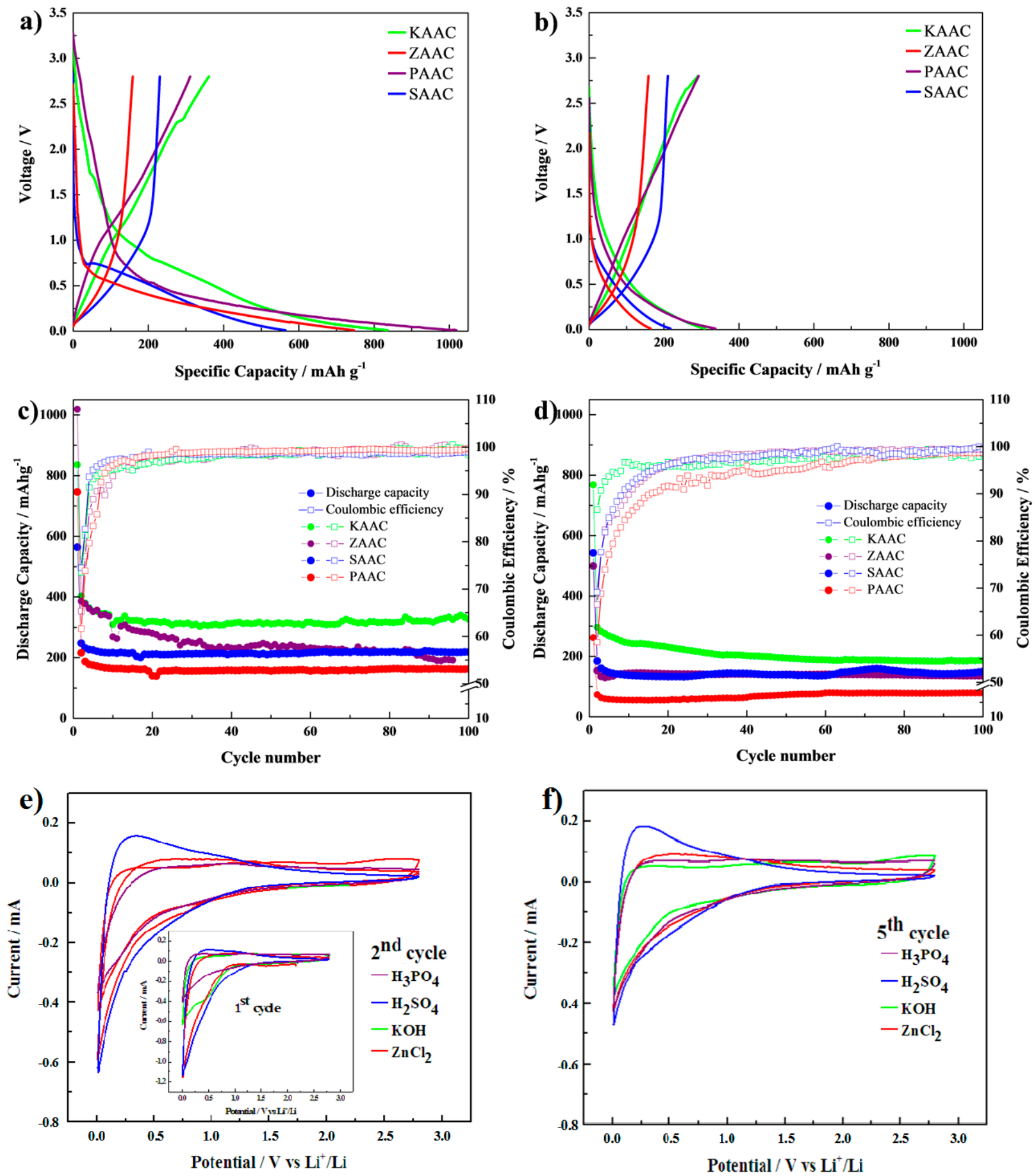

Figure 5. Cycling performances of $\mathrm{AC}$ electrodes (a) at 1 st cycle at $0.1 \mathrm{C}$ rate; (b) at 10th cycle at $0.1 \mathrm{C}$ rate. Cycling performance with Coulombic efficiency (right $Y$-axis) of PAAC, SAAC, KAAC, and ZAAC cycled at (c) $0.1 \mathrm{C}$ rate; (d) $1 \mathrm{C}$ rate. $\mathrm{CV}$ profiles of PAAC, SAAC, KAAC, and ZAAC at a scan rate of $0.1 \mathrm{mV} \mathrm{s}^{-1}$, from 0.01 to $2.8 \mathrm{~V}$ : (e) 2 nd cycle and (f) 5 th cycle. 
Table 1. Comparison of the electrochemical characteristics of different bio-derived ACs used as anode materials for lithium-ion batteries (LIBs)

\begin{tabular}{|c|c|c|c|c|c|}
\hline AC Precursor & $\begin{array}{l}\text { Activating } \\
\text { Agent }\end{array}$ & $\begin{array}{l}\text { Measurement } \\
\text { Conditions }\end{array}$ & $\begin{array}{l}\text { Initial Capacity } \\
\quad\left(\mathrm{mAh} \mathrm{g}^{-1}\right)\end{array}$ & $\begin{array}{l}\text { Reversible Capacity } \\
\qquad\left(\mathrm{mAh} \mathrm{g}^{-1}\right)\end{array}$ & References \\
\hline Agar & $\mathrm{KOH}$ & $0.1 \mathrm{C}$ & 931 & 320 at $0.1 \mathrm{C}$ after 100 cycles & This work \\
\hline Sisal fiber & $\mathrm{KOH}$ & $0.1 \mathrm{C}$ & 646 & $\begin{array}{c}\text { Capacity loss of } 363 \text { compared to } \\
\text { initial capacity }\end{array}$ & [5] \\
\hline Corn straw & $\mathrm{CaCl}_{2}$ & $0.2 \mathrm{C}$ & 1534 & 546 at 0.2 after 100 cycles & [7] \\
\hline Shaddock peel & $\mathrm{KOH}$ & $50 \mathrm{mAg}^{-1}$ & 1284 & 673 at t $50 \mathrm{mAg}^{-1}$ after 100 cycles & [19] \\
\hline Wheat stalk & $\mathrm{KOH}$ & $0.1 \mathrm{C}$ & 502 & 139.6 at $10 \mathrm{C}$ after 3000 cycles & [21] \\
\hline Green tea wastes & $\mathrm{KOH}$ & $0.1 \mathrm{~A} / \mathrm{g}$ & 706 & 400 at $0.1 \mathrm{~A} / \mathrm{g}$ after 100 cycles & [23] \\
\hline Jute fiber & $\mathrm{ZnCl}_{2}$ & $0.2 \mathrm{C}^{\circ}$ & 2117 & 742.7 at $0.2 \mathrm{C}$ after 100 cycles & [32] \\
\hline Pomelo peels & - & $90 \mathrm{mAg}^{-1}$ & 756 & 452 at $90 \mathrm{mAg}^{-1}$ after 200 cycles & [44] \\
\hline Bamboo chopsticks & $\mathrm{KOH}$ & $\sim 0.37 \mathrm{C}$ & $\sim 500$ & $\sim 360$ at $\sim 0.37 \mathrm{C}$ after 100 cycles & [45] \\
\hline Cherry pit & $\mathrm{KOH}$ & $\mathrm{C} / 3$ & - & 210 at C/3 after 200 cycles & [48] \\
\hline
\end{tabular}

To determine the structural stability of the activated carbon anodes, the electrodes were analyzed by SEM before and after 20 cycles. SEM images show that the electrodes before and after cycles have a rough surface with many pores, which indicates the stability of the electrodes (Figure S3). In order to further explain the reversible surface redox reaction at the porous anode, the CVs of the SAAC anode were performed at various scan rates (Figure S4a). The linkage between peak currents and scan rates, which is almost linear with a correlation of 0.999 , was studied using redox peaks of roughly $0.64 \mathrm{~V}$ (Figure S4b). This result shows that the redox reaction is surface-limited rather than diffusion-limited [50]. As indicated earlier, porous carbon materials have a large surface area. As follows, the quantity of oxygen-containing functional groups and other functional groups on the surface of carbon corresponds to the surface area of the porous material. The beforementioned oxygen-containing functional groups participate in the redox reaction with lithium-ion, schematically described as: $\mathrm{C}=\mathrm{O}+\mathrm{Li}^{+}+\mathrm{e}^{-}=>\mathrm{C}-\mathrm{O}-\mathrm{Li}$. Consequently, the pseudo-capacitive effect, prompted by surface reactions, has a significant effect on the advancement of electrochemical energy storage. Moreover, this effect might explain the high specific capacity and excellent performance of the activated porous carbon materials in lithium-ion batteries [51].

Furthermore, the rate performance of samples was investigated by charging and discharging the cells at various current densities between 0.1 and $10 \mathrm{C}$ each for 5 cycles as illustrated in Figure 6. At a current density of $0.1 \mathrm{C}$, the specific discharge capacities of KAAC, PAAC, SAAC, and ZAAC were 359, 331, 232, and $161 \mathrm{mAh} \mathrm{g}^{-1}$, respectively. Although the specific capacity of the samples reduced upon increasing the cycling current density to $0.5,1,2,5$, and $10 \mathrm{C}$, the cells could recover their original value when the current density was changed back to $0.1 \mathrm{C}$. The pore system and large $\mathrm{S}_{\mathrm{BET}}$ of the samples are likely to facilitate the rapid transfer of Li-ions and enhance the rate characteristics. 


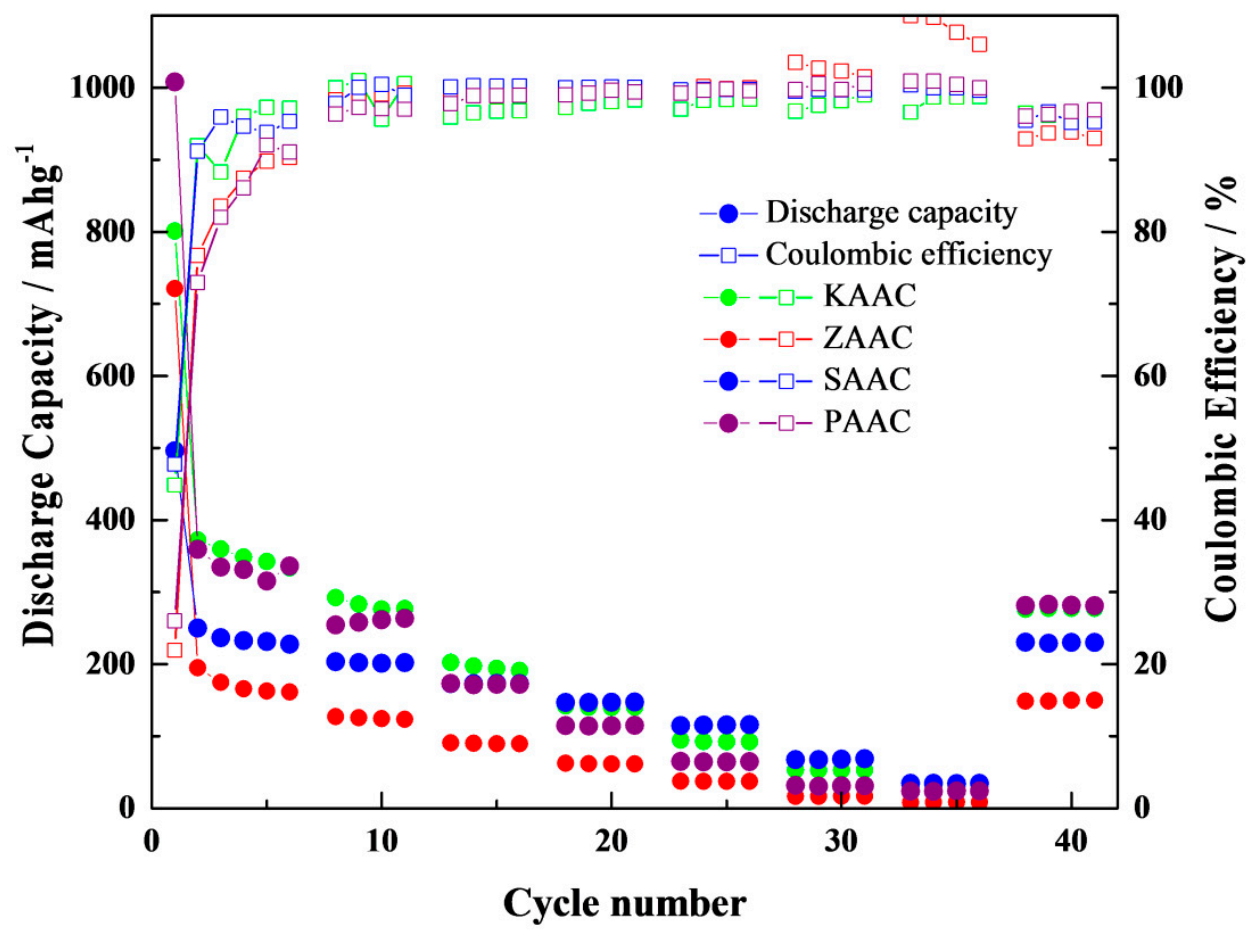

Figure 6. Rate capability of $\mathrm{AC}$ electrodes with $\mathrm{ZnCl}_{2}, \mathrm{H}_{2} \mathrm{SO}_{4}, \mathrm{KOH}$, and $\mathrm{H}_{3} \mathrm{PO}_{4}$ activators from 0.1 to $10 \mathrm{C}$.

\section{Conclusions}

In summary, we have successfully prepared low-cost and sustainable ACs using a renewable agar precursor activated by four different activators. Through investigating the effect of the activators on the morphology of AC, it was found that the AC anode obtained with $\mathrm{KOH}$ as an activating agent achieved the best electrochemical performance. The initial discharge capacity of AC with $\mathrm{KOH}$ reached $931 \mathrm{mAh} \mathrm{g}^{-1}$ and a reversible capacity of $326 \mathrm{mAh} \mathrm{g}^{-1}$ was delivered over 100 cycles at $0.1 \mathrm{C}$. The Coulombic efficiency remained above $96 \%$ after 10 cycles. Furthermore, all prepared samples exhibited excellent capacity retention and reversibility upon prolonged cycling and high rate capability. This research demonstrates a simple and effective method for preparation of mesoporous AC, and provides an effective synthesis route for a production of unique $3 \mathrm{D}$ templates that can be used to host various electrode materials.

Supplementary Materials: The following are available online at https:/ /www.mdpi.com/article/ 10.3390/nano12010022/s1, Figure S1: XPS spectra of (a) KAAC; (b) ZAAC; (c) PAAC; (d) SAAC, Figure S2: TEM images of ACs with four different activating agents: (a) SAAC; (b) PAAC; (c) KAAC; (d) ZAAC, Figure S3: SEM images of pristine electrodes: (a) KAAC, (c) PAAC, (e) ZAAC, and (g) SAAC, and electrodes after 20 cycles: (b) KAAC, (d) PAAC, (f) ZAAC, and (h) SAAC, Figure S4: (a) CV curves of SAAC electrodes at various scan rates of $1.0 \mathrm{mV} \mathrm{s}^{-1}, 1.5 \mathrm{mV} \mathrm{s}^{-1}$, and $2.0 \mathrm{mV} \mathrm{s}^{-1}$; (b) Relationship between the redox peak current and scanning rates.

Author Contributions: Conceptualization, N.I., A.N. and G.K.; Methodology, N.I., A.N. and G.K.; Validation, G.K.; Investigation, all authors; Data curation, N.I. and A.N.; Writing-original draft preparation, N.I., A.N. and G.K.; Writing—review and editing, N.I. and G.K.; Funding acquisition, Z.B. All authors have read and agreed to the published version of the manuscript.

Funding: This research was funded by the research grants OPFE2021001 "New materials and devices for defense and aerospace applications" from the Ministry of Digital Development, Innovations and Aerospace Industry of the Republic of Kazakhstan and 091019CRP2114 "Three-Dimensional All Solid State Rechargeable Batteries", 240919FD3914 "Self-Charging Rechargeable Lithium-ion Battery" from Nazarbayev University, and AP08052143 "Development of wearable self-charging power unit" from the Ministry of Education and Science of the Republic of Kazakhstan. 
Data Availability Statement: The data presented in this study are available on request from the corresponding author.

Conflicts of Interest: The authors declare no conflict of interest.

\section{References}

1. Kang, K.; Meng, Y.S.; Breger, J.; Grey, C.P.; Ceder, G. Electrodes with High Power and High Capacity for Rechargeable Lithium Batteries. Science 2006, 311, 977-980. [CrossRef]

2. Lecce, D.D.; Verrelli, R.; Hassoun, J. Lithium-ion batteries for sustainable energy storage: Recent advances towards new cell configurations. Green Chem. 2017, 19, 3442-3467. [CrossRef]

3. Hu, M.; Pang, X.; Zhou, Z. Recent progress in high-voltage lithium ion batteries. J. Power Sources 2013, 237, 229-242. [CrossRef]

4. $\quad$ Chen, W.; Zhou, Z.; Wang, R.; Wu, Z.; Liang, H.; Shao, L.; Shu, J.; Wang, Z. High performance Na-doped lithium zinc titanate as anode material for Li-ion batteries. RSC Adv. 2015, 5, 49890-49898. [CrossRef]

5. Yu, X.; Zhang, K.; Tian, N.; Qin, A.; Liao, L.; Du, R.; Wei, C. Biomass carbon derived from sisal fiber as anode material for lithium-ion batteries. Mater. Lett. 2015, 142, 193-196. [CrossRef]

6. Scrosati, B.; Hassoun, J.; Sun, Y.K. Lithium-ion batteries. A look into the future. Energy Environ. Sci. 2011, 4, 3287-3295. [CrossRef]

7. Yu, K.; Wang, J.; Wang, X.; Liang, J.; Liang, C. Sustainable application of biomass by-products: Corn straw-derived porous carbon nanospheres using as anode materials for lithium ion batteries. Mater. Chem. Phys. 2020, 243, 122644. [CrossRef]

8. Kamali, A.R.; Fray, D.J. Tin-based materials as advanced anode materials for lithium ion batteries: A review. Rev. Adv. Mater. Sci. 2011, 27, 14-24.

9. Nurpeissova, A.; Adi, A.; Aishova, A.; Mukanova, A.; Kim, S.S.; Bakenov, Z. Synergistic effect of 3D current collector structure and $\mathrm{Ni}$ inactive matrix on the electrochemical performances of Sn-based anodes for lithium-ion batteries. Mater. Today Energy 2020, 16, 100397. [CrossRef]

10. Poizot, P.; Laruelle, S.; Grugeon, S.; Dupont, L.; Tarascon, J. Nano-sized transition-metal oxides as negative-electrode materials for lithium-ion batteries. Nature 2000, 407, 496-499. [CrossRef]

11. Zhou, L.; Xu, H.; Zhang, H.; Yang, J.; Hartono, S.B.; Qian, K.; Zou, J.; Yu, C. Cheap and scalable synthesis of $\alpha$-Fe2O3 multi-shelled hollow spheres as high-performance anode materials for lithium ion batteries. Chem. Commun. 2013, 49, 8695-8697. [CrossRef]

12. Zhao, Y.; Li, X.; Yan, B.; Xiong, D.; Li, D.; Lawes, S.; Sun, X.L. Recent Developments and Understanding of Novel Mixed Transition-Metal Oxides as Anodes in Lithium Ion Batteries. Adv. Energy Mater. 2016, 6, 1502175. [CrossRef]

13. Li, Q.; Zhu, S.; Lu, Y. 3D Porous Cu Current Collector/Li-Metal Composite Anode for Stable Lithium-Metal Batteries. Adv. Funct. Mater. 2017, 27, 1606422. [CrossRef]

14. Liu, S.; Hou, H.; Liu, X.; Hu, W.; Yan, C.; Duan, J.; Meng, R. High-performance hierarchical homologous scale-like CuCl/Cu foam anode for lithium ion battery. Ceram. Int. 2016, 42, 8310-8315. [CrossRef]

15. Nurpeissova, A.; Mukanova, A.; Kalimuldina, G.; Umirov, N. Onion-Structured Si Anode Constructed with Coating by Li4Ti5O12 and Cyclized-Polyacrylonitrile for Lithium-Ion Batteries. Nanomaterials 2020, 10, 1995. [CrossRef]

16. Hwang, S.Y.; Lee, H.R.; Lee, Y.K.; Lee, G.B.; Lee, S.; Kim, H.J.; Joh, H.I. Stable fast-charging electrodes derived from hierarchical porous carbon for lithium-ion batteries. Int. J. Energy Res. 2021, 45, 4718-4726. [CrossRef]

17. Gao, F.; Geng, C.; Xiao, N.; Qu, J.; Qiu, J. Hierarchical porous carbon sheets derived from biomass containing an activation agent and in-built template for lithium ion batteries. Carbon 2018, 139, 1085-1092. [CrossRef]

18. Titirici, M.M.; White, R.J.; Brun, N.; Budarin, V.L.; Su, D.S.; Monte, F.D.; Clark, J.H.; MacLachlan, M.J. Sustainable carbon materials Chem. Soc. Rev. 2015, 44, 250-290. [CrossRef] [PubMed]

19. Li, R.; Huang, J.; Li, J.; Cao, L.; Zhong, X.; Yu, A.; Lu, G. Nitrogen-doped porous hard carbons derived from shaddock peel for high-capacity lithium-ion battery anodes. J. Electroanal. Chem. 2020, 862, 114044. [CrossRef]

20. Alam, M.M.; Hossain, M.A.; Hossain, M.D.; Johir, M.A.H.; Hossen, J.; Rahman, M.S.; Zhou, J.L.; Hasan, A.T.M.; Karmakar, A.K.; Ahmed, M.B. The potentiality of rice husk-derived activated carbon: From synthesis to application. Processes 2020, 8, 203. [CrossRef]

21. Zhou, X.; Chen, F.; Bai, T.; Long, B.; Liao, Q.; Ren, Y.; Yang, J. Interconnected highly graphitic carbon nanosheets derived from wheat stalk as high performance anode materials for lithium ion batteries. Green Chem. 2016, 18, 2078-2088. [CrossRef]

22. Sevilla, M.; Fuertes, A.B. Graphitic carbon nanostructures from cellulose. Chem. Phys. Lett. 2010, 490, 63-68. [CrossRef]

23. Sekar, S.; Lee, Y.; Kim, D.Y.; Lee, S. Substantial LIB anode performance of graphitic carbon nanoflakes derived from biomass green-tea waste. Nanomaterials 2019, 9, 871. [CrossRef]

24. Wang, H.; Yi, H.; Zhu, C.; Wang, X.; Fan, H.J. Functionalized highly porous graphitic carbon fibers for high-rate supercapacitive electrodes. Nano Energy 2015, 13, 658-669. [CrossRef]

25. Zhu, L.; Jiang, H.; Yang, Q.; Yao, S.; Shen, X.; Tu, F. An effective porous activated carbon derived from puffed corn employed as the separator coating in a lithium-sulfur battery. Energy Technol. 2019, 7, 1900752. [CrossRef]

26. Yang, J.; Zuo, S. Facile synthesis of graphitic mesoporous carbon materials from sucrose. Diam. Relat. Mater. 2019, 95, 1-4. [CrossRef]

27. Zaini, M.A.A.; Zhi, L.L.; Hui, T.S.; Amano, Y.; Machida, M. Effects of physical activation on pore textures and heavy metals removal of fiber-based activated carbons. Mater. Today Proc. 2020, 39, 917-921. [CrossRef] 
28. Nahil, M.A.; Williams, P.T. Pore characteristics of activated carbons from the phosphoric acid chemical activation of cotton stalks. Biomass Bioenergy 2012, 37, 142-149. [CrossRef]

29. Wang, A.; Sun, K.; Xu, R.; Sun, Y.; Jiang, J. Cleanly synthesizing rotten potato-based activated carbon for supercapacitor by self-catalytic activation. J. Clean. Prod. 2021, 283, 125385. [CrossRef]

30. Ao, W.; Fu, J.; Mao, X.; Kang, Q.; Ran, C.; Liu, Y.; Zhang, H.; Gao, Z.; Li, J.; Liu, G.; et al. Microwave assisted preparation of activated carbon from biomass: A review. Renew. Sustain. Energy Rev. 2018, 92, 958-979. [CrossRef]

31. Kong, L.; Peng, H.J.; Huang, J.Q.; Zhang, Q. Review of nanostructured current collectors in lithium-sulfur batteries. Nano Res. 2017, 10, 4027-4054. [CrossRef]

32. Dou, Y.; Liu, X.; Wang, X.; Yu, K.; Liang, C. Jute fiber based micro-mesoporous carbon: A biomass derived anode material with high-performance for lithium-ion batteries. Mater. Sci. Eng. B 2021, 265, 115015. [CrossRef]

33. Sankar, S.; Saravanan, S.; Ahmed, A.T.A.; Inamdar, A.I.; Im, H.; Lee, S.; Kim, D.Y. Spherical activated-carbon nanoparticles derived from biomass green tea wastes for anode material of lithium-ion battery. Mater. Lett. 2019, 240, 189-192. [CrossRef]

34. Wang, J.; Kaskel, S. KOH activation of carbon-based materials for energy storage. J. Mater. Chem. 2012, 22, 23710-23725. [CrossRef]

35. Dai, Y.Q.; Li, G.C.; Li, X.H.; Guo, H.J.; Wang, Z.X.; Yan, G.C.; Wang, J.X. Ultrathin porous graphitic carbon nanosheets activated by alkali metal salts for high power density lithium-ion capacitors. Rare Met. 2020, 39, 1364-1373. [CrossRef]

36. Zhang, L.; Gu, H.; Sun, H.; Cao, F.; Chen, Y.; Chen, G.Z. Molecular level one-step activation of agar to activated carbon for high performance supercapacitors. Carbon 2018, 132, 573-579. [CrossRef]

37. Zhang, M.; Cheng, J.; Zhang, L.; Li, Y.; Chen, M.; Chen, Y.; Shen, Z. Activated carbon by one-step calcination of deoxygenated agar for high voltage lithium ion supercapacitor. ACS Sustain. Chem. Eng. 2020, 8, 3637-3643. [CrossRef]

38. Han, S.W.; Jung, D.W.; Jeong, J.H.; Oh, E.S. Effect of pyrolysis temperature on carbon obtained from green tea biomass for superior lithium ion battery anodes. Chem. Eng. J. 2014, 254, 597-604. [CrossRef]

39. Yang, Z.; Gleisner, R.; Mann, D.H.; Xu, J.; Jiang, J.; Zhu, J.Y. Lignin Based Activated Carbon Using H ${ }_{3}$ PO 4 Activation. Polymers 2020, 12, 2829. [CrossRef]

40. Laksaci, H.; Khelifi, A.; Trari, M.; Addoun, A. Synthesis and characterization of microporous activated carbon from coffee grounds using potassium hydroxides. J. Clean. Prod. 2017, 147, 254-262. [CrossRef]

41. Li, M.; Li, W.; Liu, S. Hydrothermal synthesis, characterization, and KOH activation of carbon spheres from glucose. Carbohydr. Res. 2011, 346, 999-1004. [CrossRef] [PubMed]

42. Vu, D.L.; Seo, J.S.; Lee, H.Y.; Lee, J.W. Activated carbon with hierarchical micro-mesoporous structure obtained from rice husk and its application for lithium-sulfur batteries. RSC Adv. 2017, 7, 4144-4151. [CrossRef]

43. Ng, S.W.L.; Yilmaz, G.; Ong, W.L.; Ho, G.W. One-step activation towards spontaneous etching of hollow and hierarchical porous carbon nanospheres for enhanced pollutant adsorption and energy storage. Appl. Catal. B Environ. 2018, 220, 533-541. [CrossRef]

44. Sun, X.; Wang, X.; Feng, N.; Qiao, L.; Li, X.; He, D. A new carbonaceous material derived from biomass source peels as an improved anode for lithium ion batteries. J. Anal. Appl. Pyrolysis 2013, 100, 181-185. [CrossRef]

45. Jiang, J.; Zhu, J.; Ai, W.; Fan, Z.; Shen, X.; Zou, C.; Liu, J.; Zhang, H.; Yu, T. Evolution of disposable bamboo chopsticks into uniform carbon fibers: A smart strategy to fabricate sustainable anodes for Li-ion batteries. Energy Environ. Sci. 2014, 7, 2670-2679. [CrossRef]

46. Zhang, D.; Wang, G.; Xu, L.; Lian, J.; Bao, J.; Zhao, Y.; Qiu, J.; Li, H. Defect-rich N-doped porous carbon derived from soybean for high rate lithium-ion batteries. Appl. Surf. Sci. 2018, 451, 298-305. [CrossRef]

47. Ou, J.; Yang, L.; Zhang, Z.; Xi, X. Nitrogen-doped porous carbon derived from horn as an advanced anode material for sodium ion batteries. Microporous Mesoporous Mater. 2017, 237, 23-30. [CrossRef]

48. Hernández-Rentero, C.; Marangon, V.; Olivares-Marín, M.; Gómez-Serrano, V.; Caballero, Á.; Morales, J.; Hassoun, J. Alternative lithium-ion battery using biomass-derived carbons as environmentally sustainable anode. J. Colloid Interface Sci. 2020, 573, 396-408. [CrossRef]

49. Zhang, Y.; Chen, L.; Meng, Y.; Xie, J.; Guo, Y.; Xiao, D. Lithium and sodium storage in highly ordered mesoporous nitrogen-doped carbons derived from honey. J. Power Sources 2016, 335, 20-30. [CrossRef]

50. Hong, K.L.; Qie, L.; Zeng, R.; Yi, Z.Q.; Zhang, W.; Wang, D.; Yin, W.; Wu, C.; Fan, Q.J.; Zhang, W.X.; et al. Biomass derived hard carbon used as a high performance anode material for sodium ion batteries. J. Mater. Chem. A 2014, 2, 12733-12738. [CrossRef]

51. Byon, H.R.; Gallant, B.M.; Lee, S.W.; Shao-Horn, Y. Role of oxygen functional groups in carbon nanotube/graphene freestanding electrodes for high performance lithium batteries. Adv. Funct. Mater. 2013, 23, 1037-1045. [CrossRef] 